\title{
FinANCIAL LITERACY AND RETIREMENT PlanNing in Germany
}

Tabea Bucher-Koenen, Annamaria Lusardi

๑ Mea-Mannheim Research Institute for the Economics of Aging

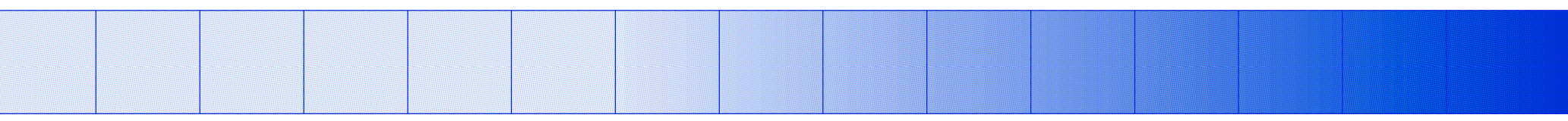

L13, 17_D-68131 Mannheim_Phone +49 621 181-2773/1862_Fax +49 621 181-1863_www.mea.uni-mannheim.de 


\title{
Financial Literacy and Retirement Planning in Germany*
}

\author{
Tabea Bucher-Koenen ${ }^{\mathrm{a}}$ \\ MEA, University of Mannheim, Dartmouth College, and Netspar
}

Annamaria Lusardi ${ }^{\mathrm{b}}$

Dartmouth College, George Washington University, and Netspar

January 31,2011

\begin{abstract}
We examine financial literacy in Germany using data from the SAVE survey. We find that knowledge of basic financial concepts is lacking among women, the less educated, and those living in East Germany. In particular, those with low education and low income in East Germany have little financial literacy compared to their West German counterparts. Interestingly, there is no gender disparity in financial knowledge in the East. In order to investigate the nexus of causality between financial literacy and retirement planning we develop an IV strategy by making use of regional variation in the financial knowledge of peers. We find a positive impact of financial knowledge on retirement planning.
\end{abstract}

Keywords: financial sophistication, retirement planning, life-cycle savings, financial education, East Germany

JEL Classification: D91

* The research reported herein was conducted pursuant to a grant from Netspar. We would like to thank Axel Börsch-Supan, Elsa Fornero, Martin Gasche, Michael Haliassos, Mike Hurd, Alex Lefter, Chiara Monticone, Kathrin Nies and Guglielmo Weber for their helpful comments. We are grateful to seminar participants at the Mathematical and Statistical Methods for Actuarial Sciences and Finance conference in Ravello, Italy, April 2010, at the Netspar Pension Workshop in Zurich, Switzerland, 2010, and at the CeRP Workshop "Financial Literacy around the World" in Turin, Italy, December 2010. This paper was started while Tabea visited Dartmouth College in the fall of 2009 and CeRP in February 2010 and she thanks both institutions for their hospitality and CDSE for financial support. We are particularly grateful to the German Research Foundation (Deutsche Forschungsgemeinschaft) for financing the SAVE survey.

a MEA, University of Mannheim, 68131 Mannheim, Germany. Email: bucher@mea.unimannheim.de.

${ }^{\mathrm{b}}$ The George Washington School of Business, Washington, DC 20052. Email: alusardi@gwu.edu and Dartmouth College. 


\section{Introduction}

Financial literacy has become an important topic in Germany. The reasons for this are manifold. One important aspect is the recent reform of the German public pension system that transformed the monolithic system into a multi-pillar system and increased individuals' responsibility to provide privately for their retirement. ${ }^{1}$ The German public pension system covers all private and public employees, i.e., about $85 \%$ of the workforce. ${ }^{2}$ It is organized as a pay-as-you-go system and currently provides for about $90 \%$ of retirement income. ${ }^{3}$ Until the recent reforms, the German pension system was famous for its generosity. However, in light of the demographic changes that will cause a steep increase in the old-age dependency ratio in the coming years, fundamental changes are deemed necessary to ensure the sustainability of the system. After basic adjustments in 1992 and 1998, in 2001, to bridge the gap that arises in retirement income, the so-called Riester scheme - a state-subsidized but voluntarily funded pillar — was introduced.

Every person that may be affected by the prospective decrease of first-pillar pensions is eligible for Riester subsidies. ${ }^{4}$ The fundamental concept is that savers contribute $4 \%$ (at least $€ 60)$ of their income to a certified private savings contract and receive a lump-sum subsidy of (since 2008$) € 154$. Families with children receive $€ 185$ for each child ( $€ 300$ if the child was born after 2007). The Riester scheme is particularly generous for individuals with low income and families with children, who can obtain subsidies of well over $90 \%$ of their contribution. ${ }^{5}$ However, despite the high subsidies for the poorest, the participation in the Riester scheme among households with low income is still low (Bucher-Koenen (2010)). More than $70 \%$ of the poorest households do not own any kind of supplementary private pensions. In the higher income quartiles this share is substantially lower: Just $20 \%$ of the households with high income do not own supplementary private pensions. Additionally, households with low income show lower levels of financial literacy, even after controlling for differences in socioeconomic status. Thus, the question has been raised about whether more than financial incentives are needed in order to get the poorest households with the least knowledge about financial issues to save.

\footnotetext{
${ }^{1}$ For an overview of the reforms of the German pension system, see Börsch-Supan and Wilke (2004).

${ }^{2}$ Civil servants have their own pension system and self-employed individuals can either self-insure or contribute to the public system.

${ }^{3}$ See e.g. Börsch-Supan and Wilke (2006).

${ }^{4}$ Currently about 38 million individuals have been estimated to be eligible (Fassauer and Toutaoui (2009)) and, at the end of 2009, about 12.9 million Riester contracts were signed (BMAS (2009)). ${ }^{5}$ See e.g. Sommer (2007), Gasche (2008). For more information see also Börsch-Supan et al. (2008) and Coppola and Reil-Held (2009).
} 
A second reason for the public discussion about financial knowledge in Germany is the rapid development of financial markets with complex products that are available to everyone. Individuals are able to buy products they often do not understand, and most demonstrate an inability to judge the quality of financial advice they receive about these products. This topic seems particularly important in light of the 2007/2008 financial crisis. Even though the majority of households did not suffer from financial losses due to the crisis-only abut $20 \%$ of private households lost part of their financial wealth due to the crisis and fewer than $4 \%$ of households lost more than $10 \%$ of their wealth - the public discussion about the financial crisis has caused major insecurity among private households with respect to their saving and investment strategies. ${ }^{6}$ Changes in consumer protection are currently under discussion in Germany. ${ }^{7}$

The objective of our study is threefold. First, we use SAVE, a survey of German households, to provide an overview of the level of financial literacy in Germany as measured by three questions on financial literacy that have been used in surveys around the world. More specifically, we analyze financial knowledge and identify groups at risk of low financial knowledge. Additionally, we link financial knowledge to retirement planning. Analyzing the relationship between financial literacy, retirement planning, and country-specific differences in the institutional context will provide the opportunity to improve the understanding of how financial knowledge is acquired and its impact on decision making.

Second, we compare financial literacy in East and West Germany. The unique setup of German unification gives us the opportunity to investigate differences in financial literacy between two German regions with distinct economic structure whose residents have different experiences in financial decision making. Due to the communist centrally managed economy, individuals in the East have only attained experience in financial decision making and accumulated financial knowledge within the last 20 years (see Sauter (2009)). We can examine whether East Germans were able to catch up with the West with respect to financial knowledge. Moreover, we compare the level of financial knowledge of specific groups in East and West in order to understand who is better at closing the gap in knowledge and experience.

Third, we contribute to the literature by addressing the problem of causality between financial literacy and financial planning. We make use of an instrumental variables (IV)

\footnotetext{
${ }^{6}$ For information on the effects of the financial crisis see, e.g., Bucher-Koenen and Ziegelmeyer (2011) and Börsch-Supan et al. (2009a).

${ }^{7}$ See for example the initiative by the Bundesverbraucherzentrale (consumer protection agency) to integrate consumer protection as a major objective when reforming banking supervision (www.vzbv.de/go/dokumente/917/3/10/index.html).
} 
approach and exploit variation in financial knowledge at the regional level to estimate the effect of financial literacy on retirement planning.

The remainder of our paper is structured as follows: Section 2 describes the SAVE data. Section 3 provides the empirical evidence and tries to answer the questions: How financially literate are German households (3.1)? Who knows the least (3.2)? What are the differences between East and West Germany (3.3)? and, Does financial literacy matter (3.4)? Section 4 concludes.

\section{SAVE data set}

SAVE is a representative German household panel designed to improve the understanding of saving behavior. It was first conducted in 2001 by the Mannheim Research Institute for the Economics of Aging (MEA). Consecutive waves of the survey were in the field in 2003/2004 and every year since 2005. In 2009, 2,222 households were in the panel. The data were collected during the early summer of 2009. The questionnaire is in paper and pencil format. ${ }^{8}$

SAVE is a household survey. ${ }^{9}$ One person, randomly chosen from all household members who have information on household finances, answers all questions in the survey. Thus, the individual completing the questionnaire is not necessarily the household head or the person most knowledgeable about the financial situation of the household. Individuals in the sample received $€ 20$ in cash with the cover letter, independent of their participation in the survey. This procedure has been used in previous years of the survey, and due to the high stability of the panel, few households keep the money without participating.

Three questions on financial literacy were included in SAVE 2007, 2008, and 2009. ${ }^{10} \mathrm{We}$ are using the cross-section from 2009 for the analysis in this paper. The financial literacy questions in the 2009 survey were changed slightly from earlier questions to allow for comparison across countries. The share of missing answers on these questions is between $2.5 \%$ and $3.3 \%$ of the sample $(\mathrm{N}=1,117)$ for each of the three questions. We drop

\footnotetext{
${ }^{8}$ A detailed description of the scientific background, design, and results of the survey can be found in Börsch-Supan et al. (2009b).

${ }^{9}$ There are two different samples in SAVE. We restrict the analysis to households in the random route sample.

${ }^{10}$ Because individuals have been asked very similar questions several times (while the wording was the same, the list of answers to each question was different), there is the concern that individuals learn about financial matters through their participation in the survey. We tested the answering behavior over the years and did not find systematic learning effects.
} 
observations for which one or more answers are missing. Thus, we are left with 1,059 observations. $^{11}$

Table A1, describing the socioeconomic details of the households in the sample, is contained in the data appendix. The average age of our respondents is 52. The youngest individual is 22; the oldest individual is 91 years old. Fifty-three percent of the respondents are female and 35\% live in East Germany. Sixty-one percent of the sample have upper secondary education, $25 \%$ have higher degrees (tertiary or non-tertiary postsecondary education). Sample-specific weights with respect to age and income classes are constructed on the basis of the German Microzensus 2008 and are used to perform the empirical analysis. ${ }^{12}$

\section{Empirical Evidence}

\subsection{How much do individuals know?}

The three questions on financial literacy used in this study were first developed by Lusardi and Mitchell (2011) for the American Health and Retirement Study (HRS) in 2004. The exact wording is as follows:

\section{Understanding of Interest Rate (Numeracy)}

Suppose you had $€ 100$ in a savings account and the interest rate was $2 \%$ per year. After 5 years, how much do you think you would have in the account if you left the money to grow: more than $€ 102$, exactly $€ 102$, less than $€ 102$ ? Do not know. / Refusal.

\section{Understanding of Inflation}

Imagine that the interest rate on your savings account was $1 \%$ per year and inflation was $2 \%$ per year. After 1 year, would you be able to buy more than, exactly the same as, or less than today with the money in this account? Do not know. / Refusal.

\section{Understanding of Risk and Diversification}

Do you think that the following statement is true or false? Buying a single company stock usually provides a safer return than a stock mutual fund. Do not know. / Refusal.

The answers to the first question (interest) are displayed in Table 1 (Panel A) below. In the total sample $82 \%$ of all respondents correctly answered that they would have more than

\footnotetext{
${ }^{11}$ Missing information on other variables is imputed using an iterative multiple imputation procedure based on a Markov-Chain Monte-Carlo method (Schunk (2008), Ziegelmeyer (2009)). Thereby the efficiency of estimates is increased due to a larger number of observations and the item non-response bias is reduced. Five multiply imputed data sets are used for the analysis and results are derived using Rubin's method (Rubin $(1987,1996)$ ).

${ }^{12}$ Details on the construction of the weights can be found in Börsch-Supan et al. (2009b).
} 
$€ 102$ in the account. Around 7\% gave incorrect answers: 3\% thought that the amount would be exactly $€ 102$ and $3.7 \%$ expected a smaller amount. About $11 \%$ said they did not know the answer or did not want to answer this question. ${ }^{13}$ As this question is very basic and only requires rudimentary mathematical abilities, it is simple to answer for most of the German population. The calculation of compound interest is part of German school curricula and students should be familiar with it even if they have the lowest educational level. ${ }^{14}$

[Table 1 about here]

The answers to the inflation question (question 2) are shown in Table 1 (Panel B). More than $78 \%$ of participants correctly responded that the purchasing power of their savings will decrease. Around 5\% did not correctly answer this question; the majority of these individuals answered that the purchasing power of their money will stay the same $(3.8 \%)$. The share of households who do not know the answer to this question is higher than the share that do not know the interest question (17\%). To answer the second question correctly, individuals have to have a basic understanding of inflation and its impact on purchasing power of income or savings. The German Bundesbank has long followed a very conservative inflationary policy. Apart from a few inflationary periods in the 1970s and early 1980s, inflation has never exceeded 4\% and since 1995 has stayed well below 2\% in most years. Moreover, in the German Democratic Republic (GDR), inflation did not officially exist, as prices for almost all consumer goods were fixed by state plans. However, there was some hidden inflation due to the adjustment of packaging sizes, and there was inflation on the black market. Therefore, it is difficult to evaluate the experience of the East Germans with inflation before unification. All in all, the exposure to periods of high inflation is limited in the German population.

Table 1 (Panel C) shows the answers given to the third question, on risk diversification. This question was correctly answered by $62 \%$ of respondents; $6 \%$ incorrectly answered that the statement is correct. This question appears to have been difficult for many individuals: around one-third responded that they do not know the answer to this question. The knowledge of stock market risk and diversification is not part of most German high school curricula. Thus, to know about risk, one either has to have some economic or financial education or

\footnotetext{
13 "Do not know" and "refuse" was the same option. Thus, we are unable to distinguish between the two. As mentioned in the data section we drop households with missing answers despite the "refuse" option.

${ }^{14}$ For an overview of financial education in German school curricula see Reifner (2003).
} 
experience with stock investments. In the German Democratic Republic (GDR) no security markets existed (see, e.g. Sauter (2009)). Therefore, East Germans were not able to acquire experience with the stock market before 1990. However, even in West Germany, until recently, stock market capitalization was rather low compared to other European countries or the United States. Only the deregulation and centralization of the stock market during the 1990s contributed to its development. Stock market participation was much publicized in the German media in the mid-1990s when large state-owned German companies Deutsche Post and Deutsche Telekom were privatized. In particular the privatization of Deutsche Telekom induced many middle-income German households to buy stocks for the first time, known as the beginning of the "Volksaktie." ${ }^{, 15}$ Nevertheless, the share of directly and indirectly held stocks is still low in Germany compared to countries like the United States, the United Kingdom, and Sweden. Guiso et al. (2003) report that around 17\% of German households directly participated in the stock market in 1998. If one includes indirect stock holdings, this amount would only increase slightly. However, Börsch-Supan and Essig (2003) argue that there is a large overlap between direct and indirect stockholders. Thus, most German households have no or very limited stock market experience. The majority of households still hold their assets in the form of savings deposits with banks or insurance contracts. This conservative investment behavior is reflected in the answers to the third question.

The overall performance of the respondents is summarized in Table 1 (Panel D). The inflation and interest questions were correctly answered by a majority of households $(72 \%)$. However, only slightly more than half of the households $(53 \%)$ were able to give correct answers to all of the questions. About $10 \%$ of respondents do not know the answer to any of the questions (i.e., they responded incorrectly or respond "do not know"). Furthermore, 37\% of households surveyed stated that they do not know the answer to at least one of the questions and $8.4 \%$ responded "do not know" for all three questions.

Table 1 also contains the responses of individuals aged 25 to 65 in the sample. In Germany the performance of the reduced sample is very similar with regard to the interest and the inflation questions: About $72 \%$ of the respondents were able to give correct answers to these two questions. The probability of giving a correct response to the risk question is slightly higher among 25 to 65 year olds. About $67 \%$ were able to answer correctly. As a result the probability of giving three correct answers is $57 \%$.

\footnotetext{
${ }^{15}$ See Börsch-Supan and Essig (2003) for an overview of institutional details and trends in German stock market participation.
} 


\subsection{Who knows the least?}

In the previous section we analyzed the overall performance on the financial literacy task. In the following section we examine the households that display low levels of financial literacy. Table 2 shows the answers to the financial literacy questions across different socioeconomic characteristics.

[Table 2 about here]

Age. Overall, we find a hump-shaped pattern of financial literacy over age.1617 However, an analysis of responses to each individual question reveals a more diverse picture: correct answers to the interest question decline with age; correct answers to the inflation question increase with age; and correct answers to the risk question are hump-shaped over the life cycle. More specifically, individuals younger than 35 are most likely to have answered the interest question correctly. However, they are least likely to have correctly answered the inflation question. They perform second best on the risk question. Fifty-five percent of the respondents younger than 35 got all the answers right. Individuals between 36 and 50 performed best on almost all the questions (the young ones are marginally better at the inflation calculation). Overall those who are middle-aged know the most; older individuals know the least. Only $43 \%$ of respondents over age 65 were able to answer all questions correctly. However, this is mostly because they could not answer the risk question and were a little less likely to calculate correctly on the interest question compared to younger individuals. People over 65 perform second best on the inflation task. In all questions apart from inflation, the oldest participants selected "do not know" more frequently than younger ones.

Gender. We find that women perform significantly worse than men. Almost $60 \%$ of male respondents correctly answered all questions compared to $47.5 \%$ of female respondents (the difference is significant at $1 \%$ level of significance). However, it is notable that women did not give more incorrect answers than men, rather they stated "do not know" much more often. Fewer than $30 \%$ of male respondents and more than $43 \%$ of female respondents had at least

\footnotetext{
${ }^{16}$ We use a cross-section for our analysis. Thus, we are unable to differentiate between age and cohort effects. Financial literacy is most likely related to both.

${ }^{17}$ We perform simple two-sided t-tests to evaluate the differences in the means between all age groups. The differences in levels of financial literacy between the youngest and the two middle age groups are not significant. All other comparisons reveal significant differences: Below 36 vs. 65+: pvalue $0.013 ; 36-50$ vs. $51-65$ : $p$-value $0.078 ; 36-50$ vs. $65+$ : p-value $0.000 ; 51-65$ vs. $65+$ : p-value 0.011 .
} 
one "do not know" response. ${ }^{18}$ In SAVE we have the opportunity to analyze the relationship between gender and individuals' roles in financial decisions. ${ }^{19}$ Our results indicate that female single decision makers without partner have lower levels of financial literacy compared to male single decision makers without partner (significant at the 1\% level). Female respondents who decide jointly with their partner also know significantly less than the respective male respondents (significant at the 5\% level). There are no significant gender disparities for individuals who are sole decision makers and live with a partner or between men and women claiming that their partner makes the decisions. Among women, single decision makers without a partner have a significantly (at 5\%) lower probability to answer three questions correctly compared to women who decide with a partner.

Education. Financial literacy is highly correlated with education and the gradient is rather steep. Table 2 shows answers across ISCED education levels. Only $22 \%$ of the respondents with lower secondary education (the lowest level of education that a person in Germany can obtain due to compulsory schooling regulation) could correctly answer all questions. More than half of the respondents who completed upper secondary education were able to answer all of the questions. The difference between these two groups is significant at $1 \%$. Respondents with higher educational degrees (tertiary and non-tertiary postsecondary education) are significantly (at 1\%) more likely to have given three correct answers compared to respondents in the two groups with lower educational levels: They answered all questions correctly with a probability of more than $70 \%$. Taking a closer look at German educational degrees reveals that respondents with a moderate level of general education (10 to 11 years of schooling) do not perform significantly worse than individuals with a higher degree (12 to 13 years of schooling). However, respondents without an occupational degree were significantly less likely to answer the questions correctly. Moreover, respondents with university training were not more likely to correctly answer the questions than individuals with a vocational degree. Thus, the relationship between years of schooling and financial literacy is not linear.

\footnotetext{
${ }^{18}$ One concern about the gender effect in financial literacy is the following: if in surveys the household head is requested to answer the questionnaire, the selection of women who are household heads is biased toward single women and widows, due to traditional role allocations. However, as explained above, men and women are selected with equal probability for the SAVE survey. Thus, there should not be a gender selection bias.

${ }^{19}$ We differentiate between four groups of decision makers: "Single decision makers with partner", i.e. decision makers who live with a partner but decide about financial issues by themselves, "single decision makers without partner", respondents that claim that their "partner makes most financial decisions" and "joint decision makers". This can be jointly with a person outside the household. However, only 3 households decide jointly with a third party.
} 
Labor Market Status. Comparing financial literacy across labor market status shows that individuals without employment (students, unemployed, homemakers) and retired individuals know significantly less compared to those employed for a wage or salary and the self-employed (at least 5\% significance for all comparisons). Only about $45 \%$ of individuals out of the labor force were able to give three correct answers. Those employed and selfemployed have higher levels of financial literacy. They answered all three questions correctly with a probability of $62 \%$ and $67 \%$, respectively. The difference in level of knowledge between the self-employed and individuals employed for wage or salary is not significant.

East vs. West Germany. We find that individuals living in West Germany are significantly more likely to have answered every single financial literacy question correctly compared to individuals in East Germany. Overall, 58\% gave three correct answers. About $45 \%$ of the respondents in East Germany knew the answers to all of the questions. This difference is significant at $1 \% .{ }^{20}$ Individuals in East Germany were substantially more likely to report "do not know." There is no difference in the incorrect answers between East and West.

In summary, bi-variate analysis reveals the same pattern of financial literacy or illiteracy over socioeconomic groups as previous studies: women are less likely to give correct answers than men; individuals with lower educational degrees and those not in the labor force also give fewer correct answers. The pattern over age is diverse; overall there is a hump-shaped pattern of financial literacy over age. ${ }^{21}$ There are no large differences in the frequency of incorrect answers across groups, but there are substantial differences in the frequency of "do not know" responses. Thus, most of the individuals who do not know the answers actually appear to recognize their illiteracy and answer the questions accordingly.

\subsection{Financial Literacy in East and West Germany}

Even twenty years after unification there are still substantial differences between East and West Germany. Various studies examine, for example, differences in income and wealth (Fuchs-Schündeln et al. (2009)), precautionary savings (Fuchs-Schündeln and Schündeln (2005)), and stock market participation (Sauter (2009)). In a cross-country study, Jappelli (2010) finds that financial literacy slowly improves with economic development. Thus, the questions asked in this section are How large are the differences in financial literacy between

\footnotetext{
${ }^{20}$ The effect remains significantly negative (at $5 \%$ ) in a multivariate context, even when controlling for differences in education, income, wealth, etc.

${ }^{21}$ Most of the results found in the bivariate analysis remain significant in a multivariate context: women, older individuals, and individuals with lower education, income, and wealth are less likely to give three correct responses.
} 
East and West Germany? and Are the levels of financial knowledge over socioeconomic characteristics different in the East and West?

In the previous section we reported that levels of financial literacy are significantly lower in East Germany compared to West Germany. In this section we investigate the relationship between socio-demographic variables and financial literacy within and across the two German regions (Table 3).

[Table 3 about here]

Age. Within both East and West Germany, we find a hump-shaped pattern of financial literacy over age. In West Germany the 65+ age group has a significantly lower probability of giving three correct answers compared to all other age groups. Only $44 \%$ of the oldest age group in the West was able to correctly answer all questions compared to $63 \%, 65 \%$, and $58 \%$ in the youngest and the two middle age groups, respectively. The differences between the three younger age groups in the West are not significant. In East Germany, even though we find a hump-shaped pattern of financial literacy over age, the differences between the age groups are not significant. Comparing levels of financial literacy within the age classes between East and West reveals that East Germans who are younger than 66 are significantly less likely to give three correct answers compared to their West German counterparts. ${ }^{22}$ However, among elderly individuals (age 65+) there is no significant difference in the level of financial literacy in East and West; they know equally little.

Gender. The analysis of gender differences in East and West Germany reveals that women (men) in the West are significantly more likely to answer all financial literacy questions correctly compared to women (men) in the East (at 5\% (1\%) significance level). Moreover, it is interesting to note that among respondents in the West there is a strong gender difference: $65 \%$ of men and only $52 \%$ of women living in West Germany gave three correct answers (significant at 1\%). However, among respondents living in East Germany, there is no significant gender difference. On average $42 \%$ of the women and $48 \%$ of the men gave three correct answers. Thus, in East Germany women and men know equally little. ${ }^{23}$

\footnotetext{
${ }^{22}$ Younger than 36 , east vs. west: p-value $0.003 ; 36-50$, east vs. west: p-value $0.015 ; 51-65$, east vs. west: p-value 0.06 .

${ }^{23}$ One reason that has been put forward to explain the lower gender disparity in the East is that in East Germany women's labor market attachment is a lot higher than in the West. However, the gender disparity in the West remains significant when controlling for income, education, and labor market status, whereas the gender difference in the East remains insignificant.
} 
Education. When comparing financial literacy across ISCED levels in East and West Germany we find the same pattern as before: Individuals with higher education levels in the East and West were more likely to give three correct answers. One rather striking result for East Germany is that among respondents with lower secondary education, only $4 \%$ were able to answer all financial literacy questions correctly. The comparison of financial literacy between East and West reveals that the respondents with the lowest levels of education in the East know less than their counterparts in the West. The probability of individuals with lower (upper) secondary education in East Germany answering all three financial literacy questions correctly is 23 (16) percentage points lower compared to West Germans with the same educational degrees (significant at 1\%, respectively). The difference in the level of financial literacy of individuals with postsecondary non-tertiary degrees in the East and West is not significant. West Germans with tertiary education were more likely than East Germans to give three correct answers (at 10\% significance). However, for this group the difference in knowledge is smaller than for individuals with lower levels of education.

In addition to their current residence, we have information on whether respondents obtained their educational degree in the GDR, i.e. the communist part of Germany before unification (see Table 2 "GDR" vs. "non GDR"). One would expect to find that individuals who obtained their education in the GDR have lower financial literacy compared to individuals who were educated either in the East after 1990 or in the West. Our results show no significant differences between individuals with GDR education and non-GDR education. Given that there are substantial differences in the level of knowledge when differentiating according to current residence it is rather surprising that there are no differences between individuals with a GDR education and individuals with other educational degrees. ${ }^{24}$

Migration between East and West. We can use the information on whether individuals obtained their educational degree during the GDR in East Germany in combination with the information on the current residence to construct an indicator for migration between East and West. Comparing levels of financial knowledge between individuals who migrated from East to West reveals that in particular those who moved West (i.e. have a GDR education and live in the West) have higher knowledge compared to those living in the East, irrespective of GDR or non-GDR education. They have even slightly higher levels of financial literacy than their peers in the West (significant at 10\%). This might on the one hand be due to a selection effect - the more capable individuals looked for job opportunities in West Germany after

\footnotetext{
${ }^{24}$ In the multivariate regression the effect of GDR education is significantly and positively related to financial literacy. This might be because of the mathematical abilities necessary to solve the first two tasks.
} 
unification - and on the other hand due to learning from their new peers in the West. However, among the population in the East-surprisingly-respondents who obtained their education during the GDR regime are significantly (at 1\%) more likely to have given three correct answers compared to individuals living in the East with a non-GDR education. ${ }^{25}$

Labor Market Status. The pattern of financial literacy as it relates to labor market status in West Germany is very similar to the pattern found for united Germany, i.e. there is a significant difference in the probability of answering all questions correctly between individuals in and out of the labor force. In East Germany retired and unemployed individuals are less likely to give three correct answers compared to those employed for a wage or salary. The difference between those out of the labor force and the self-employed is not significant (most likely due to small sample size). Those persons not employed, employed for wage or salary, and self-employed in the West have significantly higher financial literacy compared to individuals living in the East with the same labor market status (significant at 5\%,5\%, and $10 \%$, respectively). However, there are no significant differences for retired persons between the two regions.

In summary, we find that respondents in West Germany are more likely to have answered all three questions correctly than individuals in East Germany. The differences between East and West are particularly striking among those with lower education levels (and also with low income and wealth). There is little difference in the level of financial knowledge among respondents in East and West Germany with higher education levels. However, when analyzing financial literacy in East and West Germany in more detail, we do find some slightly differing patterns. Most notably, there is no significant age pattern and there is no gender discrepancy in financial literacy in East Germany. ${ }^{26}$

\subsection{Does financial literacy matter?}

\subsubsection{Retirement Planning}

In this section, we turn to the question of whether financial literacy matters for financial decision making, specifically for retirement planning. Previous research by Ameriks et al. (2003) and Lusardi (1999) as well as Lusardi and Mitchell (2007a) and Lusardi and Beeler (2007) has shown that planning matters for the accumulation of wealth. We measure retirement planning with a simple question. The wording of the question included in SAVE 2009 is similar to the questions used in the 2004 HRS. Respondents were asked the following:

\footnotetext{
${ }^{25}$ The relationship remains significant in the multivariate analysis.

${ }^{26} \mathrm{We}$ conducted multivariate analyses for East and West Germany. The result found in the bivariate analysis largely persist in a multivariate analysis.
} 
Have you and your partner ever tried to find out how much you would have to save today to reach a certain standard of living at old-age? Yes. / No.

This question is only asked of households in which at least one of the partners is not fully retired. Thus, the following analyses are based on a sample of 677 non-retired households. ${ }^{27}$ Overall, just one-quarter of those surveyed (25.3\%) responded that they have done some retirement planning. The majority of households (74.7\%) have never tried to find out how much they should save to reach a certain standard of living in retirement. Thus, the share of planners in Germany seems rather low. Other surveys, mainly U.S. surveys on retirement planning, such as Ameriks et al. (2003), find that of samples of relatively well-educated, wealthy individuals below age $65,27 \%$ did not have a financial plan. However, given that the German public pension system has been - and for many individuals still is - rather generous, the low level of retirement planning among German households is not so surprising. But given the pension reforms mentioned above, households are increasingly in charge of their financial well-being during retirement and some planning will be required. In particular younger individuals who will be fully affected by reductions in their pension income will need to plan for retirement. ${ }^{28}$

\subsubsection{Retirement Planning and Financial Literacy}

Financial planning and financial literacy are positively correlated: Table 4 shows that households who have planned for retirement are more likely to give correct answers to all of the questions compared to households who have not planned. Overall, about $70 \%$ of the planners answered all three questions correctly versus only $54 \%$ of the non-planners. The non-planners are about twice as likely as the planners to have responded "do not know" to at least one question.

[Table 4 about here]

In order to simultaneously examine the relationship between financial planning, financial literacy, and socioeconomic characteristics we conduct multivariate analyses. As a first step, we implement a simple linear regression. The dependent variable is a dummy that indicates

\footnotetext{
${ }^{27}$ In our regressions only 647 households remain because of missing information on educational status.

${ }^{28}$ In SAVE 2010 we added a question about the confidence individuals place in the public pension system. More specifically, we asked if individuals expected to get a sufficiently high pension from the public system. Surprisingly the planners, on average, are more likely to agree with the statement that their state pension will be high enough. The non-planners are, on average, significantly more pessimistic.
} 
whether households have planned for their retirement. Financial literacy is measured in two different ways. First, we use a dummy variable that equals one if the respondent is able to answer all three financial literacy questions correctly. Second, we use a variable counting the number of correct answers, i.e. the variable can take values between 0 and 3 . In addition, we control for differences between men and women, living in East Germany, income, education, and age. Moreover, we consider marital status, the number of children in the household, and homeownership. We also include information on labor market status: one variable indicates whether a person is out of the labor force (students, homemakers, unemployed), and we include a dummy variable for self-employment. As a second step, we conduct an IV regression using instruments for financial literacy in order to examine the causal effect of financial literacy on retirement planning.

The results of the linear regression are shown in Table $5 .{ }^{29}$ In the first specification (1) financial literacy has a positive relationship to retirement planning (p-value 0.117). However, when we use the financial literacy score-taking values between 0 and 3-the effect of financial literacy on planning becomes significant at $5 \%$ (see specification 2 ). ${ }^{30}$

\section{[Table 5 about here]}

Gender does not seem to have any significant effect on financial planning, nor does marital status or the number of children in the household. We do not find significant differences in financial planning between age groups, and there are no large differences in planning across education. Retirement planning increases with income. In particular, individuals at the top of the income distribution have calculated saving and investment needs more frequently than individuals at the bottom. Not surprisingly, the self-employed are more likely to have made a plan for retirement, and individuals out of the labor force are less likely to have a plan (significant at $1 \%$ and $5 \%$, respectively).

The OLS estimates may be biased for various reasons. First, it may be that it is planning that affects financial literacy rather than the other way around: Those who have planned have acquired financial literacy, and our estimates are biased upward. Second, there might be an

\footnotetext{
${ }^{29}$ Given that retirement planning is a dichotomous variable, we also conducted probit regressions, which give very similar results.

${ }^{30} \mathrm{We}$ also conduct robustness checks with more detailed measures of financial literacy. First, we include the correct answers to the interest, inflation, and risk questions separately. We find that the single questions do not have a lot of explanatory power. Second, we use dummies for answering zero, one, two, or three questions. Here we find the largest effect of correctly answering three questions on financial planning. Therefore, we define our measure of being financially literate accordingly.
} 
omitted variable bias due to missing information on ability or motivation to think about financial topics. This will bias our estimates upward. Third, there can be measurement error in the financial literacy measure that biases the estimate downward. In order to take account of these problems, we resort to instrumental variables (IV) estimation. We use exposure to financial knowledge of others in the same region as an instrument for financial literacy. The first assumption is that individuals who are exposed to people who are financially knowledgeable become more financially knowledgeable themselves. Our second central assumption is that the financial knowledge of others is beyond the control of the respondent. Specifically, we proxy for financial knowledge of others by using political attitudes at the regional level. Kaustia and Torstila (2010) find that political attitude plays an important role in financial decision making. In particular, left-wing voters are found to have lower stock market participation compared to right-wing voters. According to the authors, this is due to a different "taste for assets," which is found to be independent of other preference parameters, like risk attitude. Van Rooij et al. (2011) show that those who do not participate in the stock market are less financially literate than those who do participate. Thus, if left-wing voters have a lower likelihood of participating in asset markets, they are less likely to be financially knowledgeable compared to right-wing voters. Therefore, the exposure to financially knowledgeable individuals in regions with a high share of left-wing voters is lower than in regions with a high share of right-wing voters. We use the voting shares for the libertarian party and the voting shares for the leftist party in the 2005 national election at the administrative district level as instruments. ${ }^{31}$

The libertarian party "Freie Demokratische Partei" (FDP) in Germany strongly favors free markets and individual responsibility. On a left-right scale, FDP would be positioned to the right of the median voter. In line with our previous argument, we expect individuals who support the FDP to be more financially knowledgeable. Nationwide the FDP achieved 9.8\% of the votes in the national election in 2005. The share of votes in the administrative districts ranged from $5.2 \%$ to $17.9 \%$. In contrast, the "Partei des Demokratischen Sozialismus" (PDS/dieLinke) is clearly a left-wing party. Therefore, we expect individuals supporting this party to display lower levels of financial knowledge, i.e., there should be a negative relationship between the voting share for PDS/dieLinke and financial literacy in the region.

\footnotetext{
${ }^{31}$ The data is obtained from the Genesis data bank of the German national statistics office. There are currently 466 administrative districts in Germany. The 647 households that are part of our analysis come from 187 different administrative districts. Participation in national elections is not mandatory in Germany, however it is considered an important duty for citizens, and participation rates are usually quite high. In the 2005 election almost $77 \%$ of the population voted. Among the regions included in our sample the minimum participation is $67 \%$, the maximum is $83 \%$.
} 
PDS/dieLinke obtained $8.7 \%$ of the votes in the 2005 national elections. The share of votes for PDS/dieLinke ranged from $2.1 \%$ to $32.7 \%$. As PDS/dieLinke is the successor party of the "Sozialistische Einheitspartei Deutschlands" (SED), the communist party governing the GDR, voting shares for them are especially high in East Germany.

The preference for certain parties in the administrative districts is correlated with economic prosperity and other regional differences. For example, FDP is known to be the party of the self-employed and wealthier sections of the population, whereas PDS/dieLinke is more popular in regions where the level of unemployment is high. In order to take account of economic conditions at the regional level, we include average income in the districts according to the national accounts of the German states (Länder) in the first and second stage of the regression.

The results of our first stage regression are reported in Table A2 in the appendix. Again we use two alternative measures of financial literacy: a dummy equal to one if three correct answers are provided (specification 3) and a variable counting the number of correct answers given (specification 4). In both specifications there is a strong, positive, and highly significant relationship between the share of voters for FDP in the region and individuals' financial literacy. However, the share of voters for PDS/dieLinke is not statistically significant. The Fvalues of the excluded instruments are $4.42(\operatorname{Prob}>\mathrm{F}=0.0122)$ in specification 3 and 5.2 (Prob $>F=0.0057)$ in specification 4, respectively. Thus, the instruments are jointly significant in both specifications. We are aware of the rather low F-values of our instruments. However, the small sample size $(\mathrm{N}=647)$ made it difficult to find a set of instruments with high predictive power.

The results of the IV regression are reported in Table 5 (specifications 3 and 4). We cluster standard errors at regional level. Our results indicate that financial literacy has a positive and significant effect on financial planning for retirement. Thus, financial literacy makes individuals plan more for retirement. The exogeneity tests are rejected, indicating that our instruments are relevant. The results of Hansen's J statistics show that overidentification restrictions are not rejected. ${ }^{32} \mathrm{We}$ are aware of the fact that our instruments are potentially weak (Staiger and Stock (1997)) and, in the following section, we conduct regressions using an alternative set of instruments.

\footnotetext{
${ }^{32} \mathrm{We}$ conducted the tests for all five imputed data sets separately. Exogeneity test are rejected at 5 percent significance in all five cases. Hansen's J are not rejected in any of the data sets.
} 


\subsubsection{Alternative Explanations and Robustness of Our Results}

One concern about the validity of our instrument is that political attitude itself is directly related to retirement planning. However, we do not use personal political attitude as an instrument for financial literacy, rather we use the voting share within the region. Personal political attitude is independent of the political attitude of individuals voting for FDP or PDS/dieLinke within the region. We think this is a plausible assumption because in Germany, voting is a very private issue.

A more subtle argument against the validity of our instrument is that the probability to select a person with certain political preferences into the sample increases with the voting share of this party within the region, i.e., there is an inherent positive correlation between individual political attitude and regional voting shares. ${ }^{33} \mathrm{We}$ do not think that this is a problem in our case, because both FDP and PDS/dieLinke are relatively small parties. They are generally not the strongest party in any of the regions. ${ }^{34}$

Moreover, it could be that individuals plan (or do not plan) for retirement because they expect that FDP (PDS/dieLinke) will be in power in the future and thus individual responsibility (state responsibility) for retirement income will be high. However, neither FDP nor PDS/dieLinke are currently in a position to fundamentally reform the pension system. Thus, we think it is plausible to assume that there is no direct effect of voting shares for those two parties in the region on individuals' retirement planning.

Aware of the difficulty of finding source of exogenous variation for financial literacy, in the new wave of SAVE (SAVE 2010), we have collected information on variables that other papers have shown could be used as instruments for financial literacy. Rooij et al. (2011) and Alessie et al. (2011) have also used information on the financial knowledge of others, such as siblings and parents. In SAVE 2010 we have information about the understanding of financial matters of respondents' parents. ${ }^{35}$ For the purpose of doing instrumental variable estimation,

\footnotetext{
${ }^{33}$ To clarify this point, imagine a rather extreme situation of having only regions with either $100 \%$ or $0 \%$ votes for FDP. In such a scenario every individual living in a region with $100 \%$ voting share for FDP would for sure be an FDP voter and individuals from the other regions would for sure be nonFDP voters. Thus, the correlation between individuals' political preferences and regional voting shares would be 1 .

${ }^{34}$ Votes for FDP range between $5.2 \%$ and $17.9 \%$ with a mean of $9.4 \%$ among the regions included in our sample. Voting shares for PDS/dieLinke range from $2.1 \%$ to $32.6 \%$ with a mean of $11.6 \%$.

${ }^{35}$ The wording of the question was the following "How would you assess the financial knowledge of your parents? Please take the parent that is or was most responsible for financial decisions (on a scale from 1 - very low to 7 - very high)." We constructed a dummy "parents fin education intermediate or high" for values of four or higher and a dummy equal to 1 if respondents did not answer this question either due to item non response (ca. 4.5\%) or due to dropping out of the sample between 2009 and 2010 (ca. 7\%). We do not impute responses for this variable.
} 
since SAVE is a panel, we have merged that information into SAVE 2009. In specifications 5 and 6 in Table 5, we report IV estimates where we have added the financial knowledge of parents to our original set of instruments. We find that respondents who do not know their parents' financial understanding have significantly lower financial knowledge. This is similar to the findings by Alessie et al. (2011). The F-value of the excluded instruments is 3.99 (specification 5) and 3.95 (specification 6). The instruments are jointly significant in both specifications (p-values of 0.0032 and 0.0065 , respectively). Also, the Hansen's J statistics show that overidentification restrictions are not rejected. Including these additional instruments does not change our results fundamentally. We find a positive and significant effect of financial literacy on retirement planning.

\section{Summary and Conclusions}

Overall, the level of financial literacy is moderate in Germany. Seventy-two percent of the households in our sample were able to correctly answer two simple questions on interest and inflation. However, only slightly more than half of household respondents were able to answer all three questions correctly. Thirty-seven percent were not able to answer at least one of the questions and accordingly reported "do not know."

We also find that women are less likely to have given correct answers than men. Individuals with lower educational degrees and those out of the labor force also gave fewer correct answers. Overall, there is a hump-shaped pattern of financial literacy over the life cycle. Respondents in East Germany have substantially lower levels of knowledge than respondents in the West-even when controlling for differences in socioeconomic background. Financial literacy in East Germany is particularly low among individuals with low educational attainment and those who are unemployed or retired. There are only small differences in knowledge between respondents with high levels of education in East and West Germany. This is an interesting result as it shows the most vulnerable groups in East and West Germany.

Finally, we find that financial literacy has an important effect on individuals' planning for retirement. In light of the recent pension reforms in Germany and increasing individual responsibility, this is an important finding. If individuals with lower financial knowledge are less likely to plan for retirement, they will be less likely to realize and fill the gap in retirement income that will result from the recent reforms. This may have dramatic effects, particularly on retirement security for individuals in East Germany because state pensions will be lower due to interrupted employment histories and high rates of unemployment. Additionally, financial literacy is particularly low among East Germans with low education 
and low income. Thus, more targeted effort and programs many be needed if these groups are to improve their understanding of financial matters and take the appropriate steps to secure adequate retirement savings.

\section{References}

Alessie, R., van Rooij M. and Lusardi, A.: 2011, Financial Literacy, Retirement Preparation and Pension Expectations in the Netherlands, in this volume.

Ameriks, J., Caplin, A. and Leahy, J.: 2003, Wealth Accumulation and the Propensity to Plan, Quarterly Journal of Economics 118, 1007-1047.

BMAS: 2009, Entwicklung der privaten Altersvorsorge (Stand III. Quartal 2009), Bundesministerium für Arbeit und Soziales.

Börsch-Supan, A., Bucher-Koenen, T., Gasche, M., Ziegelmeyer, M.: 2009a, Deutsche Privathaushalte in der Finanz- und Wirtschaftskrise - Betroffenheit und Reaktionen, MEA, Universität Mannheim, Mannheim.

Börsch-Supan, A., Coppola, M., Essig, L., Eymann, A. and Schunk, D.: 2009b, The German SAVE Study Design and Results, second edn., Mannheim Institute for the Economics of Aging (MEA).

Börsch-Supan, A. and Essig, L.: 2003, Stockholding in Germany, in L. Guiso, M. Haliassos and T. Jappelli (eds.), Stockholding in Europe, MacMillan, pp. 110-140.

Börsch-Supan, A., Reil-Held, A. and Schunk, D.: 2008, Saving Incentives, Old-age Provision and Displacement Effects: Evidence from the Recent German Pension Reform, Journal of Pension Economics and Finance 7(3), 295-319.

Börsch-Supan, A. and Wilke, C. B.: 2004, The German Public Pension System: How it was, How it will be, NBER Working Paper 10525.

Börsch-Supan, A. and Wilke, C. B.: 2006, Gratwanderungen zwischen Generationenvertrag und Eigenvorsorge: Wie Europa die Herausforderungen des demographischen Wandels annimmt, Deutsches Institut für Altersvorsorge (DIA).

Bucher-Koenen, T.: 2010, Financial Literacy and Private Old-age Provision, mimeo, MEA, University of Mannheim.

Bucher-Koenen, T. and Ziegelmeyer M.: 2011, Who Lost the Most? Financial Literacy, Cognitive Abilities and the Financial Crisis, MEA Discussion Paper 234-11.

Coppola, M. and Reil-Held, A.: 2009, Dynamik der Riester-Rente: Ergebnisse aus SAVE 2003 bis 2008, MEA Discussion Paper 195.

Fassauer, S. and Toutaoui, N.: 2009, Die Anzahl des förderberechtigten Personenkreises der Riester-Rente - eine Annäherung, Deutsche Rentenversicherung 6, 478-486.

Fuchs-Schündeln, N., Krüger, D. and Sommer, M.: 2009, Inequality Trends for Germany in the Last Two Decades: A Tale of Two Countries, MEA Discussion Paper 184-2009.

Fuchs-Schündeln, N. and Schündeln, M.: 2005, Precautionary Savings and Self-Selection: Evidence from the German Reunification "Experiment", Quarterly Journal of Economics August, 1085-1120.

Gasche, M.: 2008, Und sie lohnt sich doch! Riestern ist auch und gerade für Geringverdiener wichtig, Allianz Dresdner Economic Research Working Paper 107.

Guiso, L., Haliassos, M. and Jappelli, T.: 2003, Household Stockholding in Europe: Where Do We Stand and Where Do We Go?, Economic Policy 18(36), 123-170.

Jappelli, T.: 2010, Economic literacy: An international comparison, The Economic Journal 120(548), F429F451.

Kaustia, M. and Torstila, S.: 2010, Stock Market Aversion? Political Preferences and Stock Market Participation, Discussion Paper Aalto University. 
Lusardi, A.: 1999, Information, Expectations, and Savings for Retirement," in Henry Aaron (ed.), Behavioral Dimensions of Retirement Economics, Washington, D.C.: Brookings Institution Press and Russell Sage Foundation, pp. 81-115.

Lusardi, A. and Beeler, J.: 2007, Saving Between Cohorts: The Role of Planning, in B. Madrian, O. S. Mitchell and B. J. Soldo (eds.), Redefining Retirement: How Will Boomers Fare?, Oxford University Press, New York, pp. 271-295.

Lusardi, A. and Mitchell, O.: 2011, Financial Literacy and Planning: Implications for Retirement Wellbeing, forthcoming in Annamaria Lusardi and Olivia Mitchell (eds.), "Financial Literacy: Implications for Retirement Security and the Financial Marketplace," Oxford University Press.

Lusardi, A. and Mitchell, O.: 2007, Baby Boomer Retirement Security: The Roles of Planning, Financial Literacy, and Housing Wealth, Journal of Monetary Economics 54(1), 205-224.

Reifner, U.: 2003, Finanzielle Allgemeinbildung, Vol. Band 6, Nomos Verlagsgesellschaft.

Rubin, D. B.: 1987, Multiple Imputation for Nonresponse in Surveys, New York: Wiley.

Rubin, D. B.: 1996, Multiple Imputation After 18+ Years, Journal of the American Statistical Association 91(434), 473-489.

Sauter, N.: 2009, Tearing Down the Wall: (Non-)Participation and Habit Persistence in East German Securities Markets, mimeo, Munich Graduate School of Economics .

Schunk, D.: 2008, A Markov Chain Monte Carlo Algorithm for Multiple Imputation in Large Surveys, Advances in Statistical Analysis 92, 101-114.

Sommer, M.: 2007, Fiskalische Auswirkungen einer Erweiterung des Förderungsrahmens von Riesterrenten, MEA Discussion Paper 122.

Staiger, D. and Stock, J.: 1997, Instrumental Variable Regression with Weak Instruments, Econometrica 65, 557-586.

van Rooij, M., Lusardi, A. and Alessie, R.: 2011, Financial Literacy and Stock Market Participation, forthcoming Journal of Financial Economics.

Ziegelmeyer, M.: 2009, Documentation of the logical imputation using the panel structure of the 2003-2008 German SAVE Survey, MEA Discussion Paper 173-09. 


\section{Tables}

Table 1: Answers to the Financial Literacy Questions

This table shows summary statistics for the performance of respondents on all three financial literacy questions. In particular, it displays the frequency and the proportion of households who were able to give correct answers to the interest (Panel A), inflation (Panel B), and risk diversification (Panel C) question. Additionally, the overall performance on all three questions is summarized in panel $\mathrm{D}$. The frequency and the proportion of households who gave correct answers to the interest and the inflation question, who were able to answer all three questions, who were unable to answer any of the questions, who gave at least one "do not know" response, and who answered "do not know" to all three questions are reported.

\begin{tabular}{lcccc} 
Panel A: Interest & \multicolumn{2}{c}{ total sample } & \multicolumn{2}{c}{ age 25-65 } \\
& households & in percent & households & in percent \\
\hline more than $€ 102$ & 872 & 82.4 & 577 & 83.3 \\
exactly $€ 102$ & 31 & 3.0 & 22 & 3.3 \\
Less than $€ 102$ & 39 & 3.7 & 24 & 3.4 \\
do not know / refuse to answer & 116 & 11.0 & 70 & 10.1 \\
\hline N of obs. & 1,059 & 100.0 & 693 & 100.0 \\
\hline \hline
\end{tabular}

\section{Panel B: Inflation}

\begin{tabular}{lcccc} 
& households & in percent & households & in percent \\
\hline more & 9 & 0.9 & 9 & 1.2 \\
exactly the same & 40 & 3.8 & 27 & 3.9 \\
Less & 830 & 78.4 & 539 & 77.8 \\
do not know / refuse to answer & 180 & 17.0 & 118 & 17.1 \\
\hline N of obs. & 1,059 & 100.0 & 693 & 100.0 \\
\hline \hline
\end{tabular}

\section{Panel C: Risk}

\begin{tabular}{lcccc} 
& households & in percent & households & in percent \\
\hline "true"-incorrect & 62 & 5.9 & 33 & 4.8 \\
"false"-correct & 655 & 61.8 & 464 & 66.9 \\
do not know / refuse to answer & 342 & 32.3 & 196 & 28.3 \\
\hline N of obs. & 1,059 & 100.0 & 693 & 100.0 \\
\hline \hline
\end{tabular}

\section{Panel D: Answers across all three questions}

\begin{tabular}{lcccc} 
& households & in percent & Households & in percent \\
\hline correct answers to interest and inflation & 762 & 71.9 & 592 & 71.8 \\
all answers correct & 563 & 53.2 & 394 & 56.8 \\
no correct answer & 109 & 10.3 & 68 & 9.8 \\
at least one "do not know / refuse" & 392 & 37.0 & 232 & 33.5 \\
all "do not know / refuse" & 89 & 8.4 & 54 & 7.8 \\
\hline \hline
\end{tabular}

Source: own calculation on the basis of SAVE 2009, data is weighted. 
Table 2: Financial Literacy and Socioeconomic Variables $(\mathrm{N}=1,059)$

This table shows financial literacy across different socioeconomic variables. The first six columns show the percentage of correct answers and the percentage of "do not know" (dk) to each financial literacy question (interest, inflation, risk). The last two columns display summary performance on the financial literacy task, i.e. the percentage of respondents with three correct answers and the percentage of respondents with at least one "do not know" response.

\begin{tabular}{|c|c|c|c|c|c|c|c|c|}
\hline & \multicolumn{2}{|c|}{ Interest } & \multicolumn{2}{|c|}{ inflation } & \multicolumn{2}{|c|}{ risk } & \multicolumn{2}{|c|}{ overall } \\
\hline & correct & $\mathrm{dk}$ & correct & $\mathrm{dk}$ & correct & $\mathrm{dk}$ & correct & $\mathrm{dk}$ \\
\hline \multicolumn{9}{|c|}{ Age } \\
\hline 35 and younger & 84.6 & 11.0 & 69.5 & 22.0 & 65.6 & 30.9 & 55.3 & 36.8 \\
\hline 35 to 50 & 84.1 & 10.6 & 81.4 & 14.4 & 69.4 & 25.4 & 60.7 & 29.8 \\
\hline 51 to 65 & 83.1 & 7.7 & 79.4 & 16.2 & 64.1 & 30.8 & 53.3 & 36.1 \\
\hline older than 65 & 78.1 & 14.3 & 80.4 & 17.1 & 48.4 & 42.7 & 42.8 & 46.4 \\
\hline \multicolumn{9}{|c|}{ Gender } \\
\hline Men & 83.2 & 9.4 & 83.2 & 12.4 & 67.6 & 25.8 & 59.6 & 29.9 \\
\hline women & 81.1 & 12.4 & 74.1 & 21.0 & 56.8 & 38.0 & 47.5 & 43.3 \\
\hline \multicolumn{9}{|c|}{ Education (ISCED 1997 classification) } \\
\hline lower secondary & 57.7 & 24.6 & 53.4 & 38.6 & 33.7 & 58.8 & 21.7 & 66.0 \\
\hline upper secondary & 83.0 & 11.1 & 78.1 & 17.8 & 60.0 & 33.3 & 51.6 & 38.1 \\
\hline postsec. non-tert. & 89.4 & 6.0 & 89.2 & 6.9 & 78.7 & 15.9 & 70.1 & 21.6 \\
\hline tertiary & 90.2 & 6.0 & 91.1 & 4.9 & 76.8 & 21.0 & 72.0 & 22.0 \\
\hline other & 91.6 & 4.4 & 74.0 & 18.2 & 67.1 & 28.9 & 51.1 & 38.2 \\
\hline GDR & 81.4 & 10.7 & 80.4 & 16.4 & 64.7 & 31.8 & 55.0 & 36.6 \\
\hline Non GDR & 82.8 & 11.1 & 77.5 & 17.2 & 60.6 & 32.5 & 52.4 & 37.2 \\
\hline \multicolumn{9}{|c|}{ Labor Market Status } \\
\hline not employed & 77.0 & 16.2 & 68.5 & 25.5 & 53.3 & 43.0 & 44.6 & 49.2 \\
\hline employed for wage & 88.0 & 7.4 & 81.0 & 13.4 & 71.3 & 23.9 & 62.1 & 28.2 \\
\hline Self-employed & 86.8 & 8.0 & 87.2 & 10.7 & 79.1 & 13.9 & 66.8 & 18.8 \\
\hline retired & 77.4 & 13.1 & 79.4 & 17.7 & 51.9 & 39.7 & 44.5 & 44.2 \\
\hline \multicolumn{9}{|c|}{ East vs. West Germany } \\
\hline West & 84.9 & 9.0 & 81.8 & 13.7 & 66.2 & 27.5 & 58.0 & 32.2 \\
\hline East & 77.8 & 14.7 & 72.1 & 23.0 & 54.0 & 41.0 & 44.5 & 45.8 \\
\hline
\end{tabular}

Source: SAVE 2009, own calculation, data is weighted. 
Table 3: Financial Literacy in East and West Germany $(\mathrm{N}=1,059)$

This table displays the proportion of households who correctly answer the interest, inflation, and risk question, respectively in East and West Germany. The last two columns display the percentage of respondents with three correct answers in East and West Germany.

\begin{tabular}{|c|c|c|c|c|c|c|c|c|}
\hline & \multicolumn{2}{|c|}{ interest } & \multicolumn{2}{|c|}{ inflation } & \multicolumn{2}{|c|}{ risk } & \multicolumn{2}{|c|}{3 correct } \\
\hline & West & East & West & East & West & East & West & East \\
\hline \multicolumn{9}{|c|}{ Age } \\
\hline 35 and younger & 86.1 & 81.0 & 78.6 & 48.6 & 71.7 & 51.5 & 63.2 & 37.0 \\
\hline 35 to 50 & 88.3 & 75.5 & 83.9 & 76.1 & 73.2 & 61.6 & 65.5 & 50.8 \\
\hline 51 to 65 & 87.7 & 77.1 & 84.6 & 72.7 & 69.1 & 57.6 & 58.4 & 46.6 \\
\hline older than 65 & 77.6 & 79.1 & 79.8 & 81.6 & 51.1 & 43.4 & 44.4 & 40.0 \\
\hline \multicolumn{9}{|c|}{ Gender } \\
\hline Men & 87.4 & 75.8 & 87.1 & 74.5 & 72.6 & 56.4 & 64.8 & 48.0 \\
\hline women & 82.3 & 79.2 & 76.6 & 70.4 & 59.7 & 52.3 & 51.1 & 42.0 \\
\hline \multicolumn{9}{|c|}{ Education (ISCED 1997 classification) } \\
\hline lower secondary & 63.9 & 35.6 & 58.2 & 36.4 & 38.1 & 18.0 & 26.8 & 3.4 \\
\hline upper secondary & 86.6 & 76.9 & 83.6 & 69.0 & 64.4 & 52.7 & 57.6 & 41.5 \\
\hline postsec. non-tert. & 90.1 & 87.0 & 89.9 & 87.0 & 84.0 & 61.0 & 72.8 & 61.0 \\
\hline tertiary & 89.7 & 90.6 & 92.6 & 89.5 & 84.0 & 69.2 & 78.5 & 65.3 \\
\hline other & 94.6 & 82.7 & 76.6 & 34.0 & 75.2 & 43.2 & 58.5 & 20.6 \\
\hline GDR & 86.3 & 80.1 & 89.0 & 78.1 & 74.9 & 61.9 & 67.2 & 51.7 \\
\hline Non GDR & 84.7 & 73.1 & 81.0 & 59.8 & 65.2 & 37.8 & 56.9 & 29.7 \\
\hline \multicolumn{9}{|c|}{ Labor Market Status } \\
\hline not employed & 83.0 & 68.7 & 76.7 & 58.2 & 61.1 & 44.7 & 52.9 & 34.1 \\
\hline employed & 89.7 & 83.5 & 84.0 & 73.0 & 73.3 & 64.5 & 65.5 & 52.9 \\
\hline Self-employed & 88.6 & 83.8 & 90.0 & 82.5 & 84.5 & 69.8 & 76.5 & 50.2 \\
\hline retired & 78.1 & 76.3 & 80.0 & 78.5 & 55.6 & 45.6 & 46.7 & 40.6 \\
\hline
\end{tabular}

Source: SAVE 2009, own calculation, data is weighted.

Table 4: Retirement Planning and Financial Literacy $(\mathrm{N}=677)$

This table shows the proportion of households who correctly answer and who do not know the answer to the respective financial literacy questions across planning and not planning for retirement. Only households who have not yet retired are included in the sample.

\begin{tabular}{|c|c|c|}
\hline & planning & $\begin{array}{c}\text { not } \\
\text { planning }\end{array}$ \\
\hline \multicolumn{3}{|c|}{ Interest } \\
\hline correct & 90.9 & 82.5 \\
\hline do not know & 44.4 & 11.4 \\
\hline \multicolumn{3}{|c|}{ Inflation } \\
\hline correct & 88.4 & 75.4 \\
\hline do not know & 6.7 & 19.2 \\
\hline \multicolumn{3}{|c|}{ Risk } \\
\hline correct & 77.4 & 64.0 \\
\hline do not know & 16.4 & 32.0 \\
\hline \multicolumn{3}{|c|}{ Overall } \\
\hline inflation and interest & & \\
\hline correct & 82.9 & 69.6 \\
\hline all correct & 69.1 & 53.8 \\
\hline at least $1 \mathrm{dk}$ & 19.5 & 37.5 \\
\hline
\end{tabular}

Source: Own calculation on the basis of SAVE 2009; data is weighted. 
Table 5: Multivariate Analysis of Retirement Planning

This table reports OLS and GMM estimates of the effect of financial literacy and several control variables on retirement planning. In columns 3 and 4 financial literacy has been instrumented using voting shares for FDP and PDS/dieLinke. Columns 5 and 6 use parental financial education and voting shares for FDP and PDS/die Linke as an alternative set of instruments. "d" indicates a dummy variable. "ref." indicates the omitted category. Coefficients and standard errors are calculated using five imputed data sets and combined according to Rubin's Rule (Rubin $(1987,1996)$ ). Standard errors in the IV specifications are clustered at the regional level.

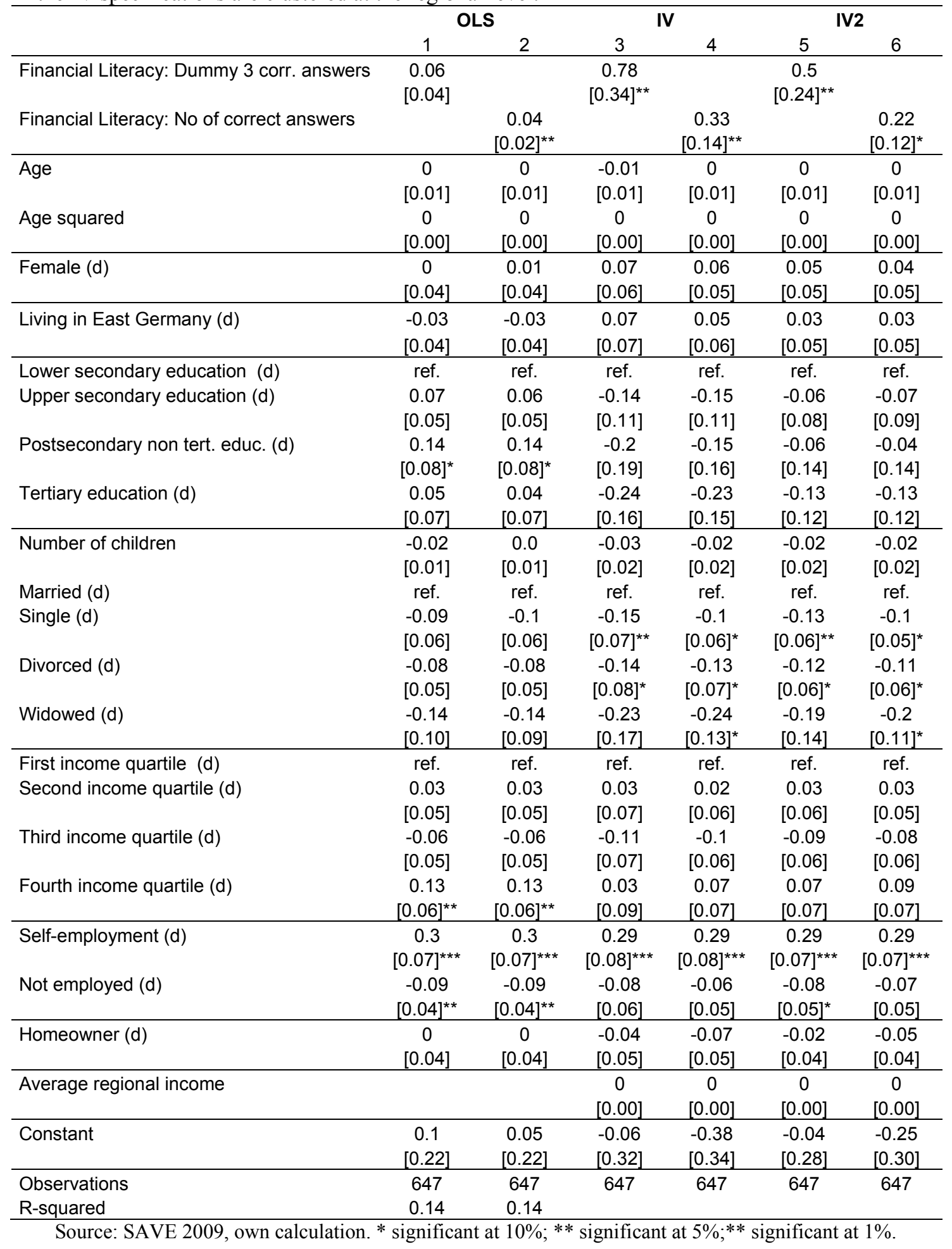




\section{Appendix}

Table A1: Summary Statistics

This table contains summary statistics for our sample. The data is imputed and weighted.

\begin{tabular}{|c|c|c|c|c|}
\hline & mean & std. dev. & $\min$ & $\max$ \\
\hline Age & 52.11 & 16.78 & 22 & 91 \\
\hline Female & 0.53 & 0.50 & 0 & 1 \\
\hline East & 0.35 & 0.48 & 0 & 1 \\
\hline Children in household & 0.35 & 0.48 & 0 & 1 \\
\hline No. of children & 1.69 & 1.42 & 0 & 10 \\
\hline \multicolumn{5}{|l|}{ Marital status } \\
\hline Married & 0.55 & 0.50 & 0 & 1 \\
\hline Single & 0.20 & 0.40 & 0 & 1 \\
\hline Divorced & 0.13 & 0.33 & 0 & 1 \\
\hline Widowed & 0.10 & 0.30 & 0 & 1 \\
\hline Separated & 0.02 & 0.15 & 0 & 1 \\
\hline \multicolumn{5}{|l|}{ Education } \\
\hline Lower secondary education & 0.10 & 0.31 & 0 & 1 \\
\hline Upper secondary education & 0.61 & 0.49 & 0 & 1 \\
\hline Postsecondary, non tertiary & 0.10 & 0.30 & 0 & 1 \\
\hline Tertiary & 0.15 & 0.35 & 0 & 1 \\
\hline Other & 0.04 & 0.20 & 0 & 1 \\
\hline \multicolumn{5}{|l|}{ Labor market status } \\
\hline Employed for wage/salary & 0.44 & 0.50 & 0 & 1 \\
\hline Self-employed & 0.05 & 0.22 & 0 & 1 \\
\hline Not employed & 0.18 & 0.39 & 0 & 1 \\
\hline Retired & 0.33 & 0.47 & 0 & 1 \\
\hline \multicolumn{5}{|l|}{ Income in $€$} \\
\hline Income per month & 2,154 & 1,485 & 0 & 15,000 \\
\hline Number of observations & 1,059 & & & \\
\hline
\end{tabular}

Table A2: First Stage Regressions

This table reports estimates of the first stage regressions of financial literacy on all the control variables used in the OLS regressions and the share of voters for FDP and PDS/dieLinke in the region. They are numbered corresponding to the second stage regressions in Table 5. In specification 3 and 4 we use the share of voters for FDP and PDS/dieLinke in the region as instruments. In specification 5 and 6 we use financial education of parents as additional instruments. "d" indicates a dummy variable. Additional controls are income quartiles, indicators for not being employed or being self-employed, gender, living in East Germany, age and age squared, marital status, number of children, homeownership and education, as specified previously. Average regional income is included as control. Coefficients and standard errors are calculated using five imputed data sets and combined according to Rubin's Rule (Rubin $(1987,1996))$. Standard errors are clustered at the regional level.

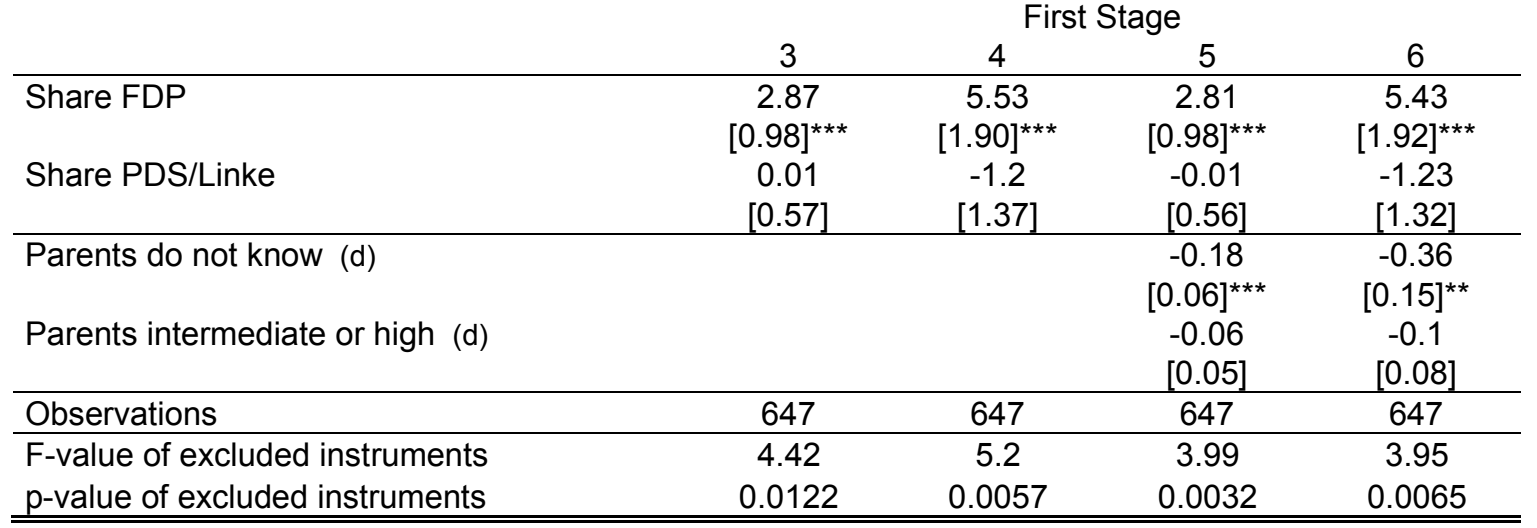

Source: SAVE 2009, own calculation. * significant at 10\%; ** significant at 5\%; *** significant at $1 \%$. 